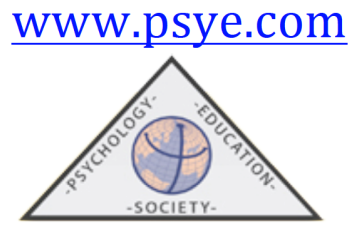

\title{
Investigating the Empirical Links between Creative and Critical Thinking ${ }^{1}$
}

\author{
Kuan-Chen TSAI
}

Asia University, Provincia de Taiwán

(Received on October 16, 2017; Accepted on July 25, 2018)

\begin{abstract}
Although traditionally creative and critical thinking have been viewed as independent skills and dispositions, several commenters have argued that both modes of thoughts can be complementary. The purpose of the current study is to examine the relationship between creative and critical thinking among Chinese art and design undergraduates in Macau. A total of 140 college students from the art and design program in Macau were recruited for our study. Two major findings were recorded. Creative and critical thinking were positively correlated among our Chinese undergraduates and this correlation was strong. Furthermore, creative thinking was similar between students from Mainland China and from Macau; nevertheless, students from Mainland China had better critical thinking abilities than students from Macau. Although there were some salient limitations in the current study, it remains of importance and value. Future research in this line of study seems promising and deserves more attention.
\end{abstract}

Keywords: creative thinking, critical thinking, art and design, Macau, Chinese undergraduates La asociación entre la composición corporal, la actividad fisica,
y la imagen corporal en modelos y controles costarricenses

RESUMEN: Aunque tradicionalmente el pensamiento creativo y crítico ha sido visto como habilidades y actitudes independientes, varios autores han argumentado que ambos modos de pensamiento pueden ser complementarios. El propósito del presente estudio es examinar la relación entre el pensamiento creativo y crítico entre los estudiantes universitarios de arte y diseño chinos en Macao. Un total de 140 estudiantes universitarios del programa de arte y diseño de Macao fueron reclutados para este estudio. Se registraron dos hallazgos importantes. El pensamiento creativo y crítico se correlacionaron positivamente entre nuestros estudiantes universitarios chinos siendo esta correlación fuerte. Además, el pensamiento creativo era similar entre los estudiantes de la China continental y de Macao; sin embargo, los estudiantes de la China continental tenían mejores capacidades de pensamiento crítico que los estudiantes de Macao. A pesar de que existen algunas limitaciones destacadas en el presente estudio, éste sigue siendo importante y valioso.

La investigación futura en esta línea de estudio parece prometedora y merece más atención.

Palabras claves: Imagen corporal, modelaje, composición corporal, hispanos, Costa Rica, actividad física, satisfacción corporal.

${ }^{1}$ This paper is founded by IEEM Academic Research Grant 2016-17. 
Address for correspondence: E-mail: tsaikuanchen@gmail.com

\section{Introduction}

The importance of creative and critical thinking in education has been discussed and underlined in previous literature (Brodin, 2016). Both modes of thinking not only affect students' learning processes (Liu, He, \& Li, 2015) and learning outcomes (Fordham, 2015), but also influence prospective teachers' teaching strategies (Koray \& Koksal, 2009). As a result, the stimulation of creative and critical thinking should be reinforced not only in the classroom but also in educational policies (Hoofd, 2010).

Although traditionally creative and critical thinking have been viewed as independent skills and dispositions, several commenters have argued that both modes of thoughts can be complementary (Karakas, 2010). This congruence viewpoint was confirmed by an empirical study, which showed that the antilogos evaluation (the ability to critically evaluate whether specific information may support different claims) involved both creative and critical thinking (Glassner \& Schwarz, 2007). Chang, $\mathrm{Li}$, Chen and Chiu's (2015) quasi-experimental study also provided valuable empirical data supporting the fact that participants who combined creative and critical thinking teaching methods showed higher performance than those who followed regular class methods.

The development of creative and critical thinking skills in students should be stressed in order to maximize learning outcomes. To this end, several methods have been used in the classroom. For example, project-based convergent programs were used successfully in secondary school science courses to facilitate both kinds of thinking as well as to stimulate students' interest in related subjects (Chun, Kang, Kim, \& Kim, 2015).

\section{Literature Review}

\section{Creative Thinking}

A number of scholars have agreed with the stance that creative thinking is a form of problem solving (Runco \& Chand, 1995; Baughman \& Mumford, 1995). For example, Torrance (1974) defined creative thinking as

A process of becoming sensitive to problems, deficiencies, gaps in knowledge, missing elements, disharmonies, and so on; identifying the difficulty; searching for solutions, making guesses, or formulating hypotheses about the deficiencies; testing and retesting these hypotheses and possibly modifying and retesting them; and finally communicating the results. (p.8)

For these proponents, complete creative thinking should include three broad stages: finding or defining problems, seeking possible solutions, and evaluating ideas.

The importance of focusing on creative thinking in education has been stressed by educators and researchers (Sternberg, 2003; Tsai, 2012). O'Donnell and Micklethwaite (1999) reviewed the educational curriculum of 16 countries and concluded that creativity was viewed as a building block of an essential skill at various educational levels. McWilliam and Dawson (2008) believed that creative thinking was an important developmental skill and should be (c) Psy, Soc, \& Educ, 2019, Vol. 11(3) 
included in appropriate pedagogical practices. In higher education, Halpern (2010) also suggested more empirical research to identify best practices for better thinkers.

With regard to the assessment of creative thinking, the most widely used instrument is probably the Torrance Test of Creative Thinking (TTCT; Torrance, 1974), which includes figural and verbal forms. The TTCT-Verbal consists of five activities: ask-and-guess, product improvement, unusual uses, unusual questions, and just suppose. The TTCT-Figural consists of three activities: picture construction, picture completion, and repeated figures of lines or circles. Four subscales are often used in related studies as indices of creative thinking: (a) fluency, the number of relevant ideas; (b) originality, the number of statistically infrequent ideas; (c) flexibility, the variety of categories of relevant responses; and (d) elaboration, the number of added ideas. According to the manual, the reliability estimates range between .89 and .94 and test-retest reliability coefficients range between .50 and .93 . In terms of construct validity, studies have shown conflicting results with regard to its dimensionality (Kim, 2006). The problem arises from its scoring system which contributes to originality scores depending heavily on fluency scores (Hocevar, 1979). In order to solve this issue, Silvia et al. (2008) provided alternative scoring approaches to minimize the influence of fluency scores on other scores.

The popular TTCT belongs to a group of divergent thinking tests whose validity of representing the creativity of individuals is often questioned (Baer \& McKool, 2014). Several scholars have argued that the method that asks participants to produce real-world creative products is the only way to represent individuals' creativity (Hocevar \& Bachelor, 1989). Following this line of thought, Amabile (1982) developed the Consensual Assessment Technique (CAT) to assess creative potential. The CAT is widely used and well validated in creativity research, especially when used in diverse experimental conditions (Baer, Kaufman, \& Gentile, 2004). Its basic procedure involves asking participants to create something, such as a poem, a collage, a story, or some kind of product. These creative products are then independently evaluated by experts without having to defend their judgments. Kaufman, Lee, Baer, and Lee (2007) explained that the CAT "focuses on creative performance, not creative thinking skills or other attributes that may be hypothesized to lead to creative performance" (p. 98). Generally, reliabilities among judges are quite satisfactory, ranging from .70 to .90 (Amabile, 1996).

\section{Critical Thinking}

Critical thinking is viewed as an important component in education platforms. Bloch and Spataro (2014) suggest that cultivating a culture of critical-thinking is a necessary approach to implementing critical thinking in the classroom. From a pedagogy viewpoint, critical thinking is viewed as a method that encourages students to take an active role in questioning and challenging the norms, which may lead to critical action toward changing the status quo (Shaw, 2014). A meta-analysis conducted by Huber and Kuncel (2016) showed that critical thinking significantly improved over the course of a normal college experience, although including critical thinking as part of the curricula did not necessarily generate incremental long-term gains.

When it comes to defining critical thinking, different scholars have different perceptions. Through a qualitative content analysis, Atabaki, Keshtiaray, and Yarmohammadian (2015) 
found that critical thinking consisted of two lines of thoughts: philosophical and psychological orientation. The former is derived from Socrates's exploratory dialogue method, in which he related critical thinking to a path to discovering the truth. Since philosophical theories emphasize on logic and reasoning in order to clarify issues, critical thinking laid a foundational thinking model to rationally and reflexively focus on beliefs and decisions. Facione, Facione, and Giancarlo (1998) thus suggest that the critical thinking model should include six thinking skills: interpretation, analysis, testing, inference, explanation, and self-regulation.

While philosophers stress on the nature and quality of critical thinking, psychologists emphasize its cognitive processes, components, and applications. From cognitive psychology and intellectual development, psychologists attempt to link critical thinking to high-level thinking skills for solving problems and gaining new information. Atabaki et al. (2015) point out that the biggest difference between the two camps on critical thinking is rooted in attitudes and skills. When Atabaki et al. investigated the concept of critical thinking in both fields, they concluded that critical thinking attitudes from a philosophical point of view involved searching the facts, open mindedness, integration, self-confidence, cognitive maturity, doubtful mentality, and curiosity. On the other hand, psychologists focus on critical thinking skills that include analysis, reasoning, inference, comparison, formulating hypotheses, synthesizing and creating new ideas, testing, and comprehensive conclusions (for a detailed review, see pp. 98-100).

With regard to the assessment of critical thinking, a number of packages are available on the market. First, there is the Critical Thinking Assessment Test (CTAT; US Department of Education, 2000), which is a 15-item test. The test questions are based on real-world scenarios that require students to exercise higher-order thinking skills. The CAT includes four components: evaluation of information, evaluation of ideas and different views, learning and problem solving, and communication of ideas. The California Critical Thinking Skills Test (CCTST; Facione, 2000) is a 34-item multiple-choice standardized test that was developed to assess critical thinking with five attributes of interest: analysis, evaluation, inference, deductive reasoning, and inductive reasoning. The CCTST consists of a total critical thinking skills score, which is considered an important predictor of success for the completion of educational programs. The Cornell Critical Thinking Tests Levels X \& Z was developed by Ennis and Millman (1985) where Level X with 78 items includes four skills: induction, deduction, credibility, and identification of assumptions, while Level $\mathrm{Z}$ with 52 items includes three additional skills: semantics, definition, and prediction in planning experiments. Ennis and Millman reported a Cronbach alpha value between the range of .87 and .91 .

\section{Purpose of the Study and Research Questions}

Although a number of empirical studies have attempted to investigate the relationship between creative and critical thinking among undergraduates, research on art and design students is rare. As such, the purpose of the current study is to examine the relationship between creative and critical thinking among Chinese art and design undergraduates in Macau. Three research questions are asked: What is the relationship between creative and critical thinking among our subjects? Does gender play a role in this relationship? In addition, there are two major groups of students in tertiary education in Macau: domestic students with a permanent residency status 
(local) who speak Cantonese, and non-domestic students from Mainland China who speak Mandarin. The two groups are ethnically similar, but have been raised in different social environments and educated differently. As a result, it is advantageous to differentiate between the two groups, and investigate whether being a Macau resident affects this relationship between critical thinking and creative thinking.

\section{Methods}

\section{Participants}

A total of 140 college students from the art and design program in Macau were recruited for our study. Among them, 62 were males and 78 were females, with 109 students from Mainland China and 31 local students from Macau. In our sample, 97 were third-year students and 43 were fourth-year students, and their average age was 21.49 years old $(S D=1.34)$. All participants were told that taking part in this project was part of the course requirement.

\section{Instruments}

Creative thinking. The Cognitive Processes Associated with Creativity (CPAC; Miller, 2009) scale was used to investigate the creative potential of our participants. The CPAC scale includes 28 items and measures six dimensions of creativity: idea manipulation, idea generation, flow, imagery/sensory perception, incubation, and metaphorical/analogical thinking. Miller (2009) reported that the internal consistency of the total scale was acceptable $(\alpha=.852)$ and its factor structure supported the six components of creativity. The concurrent validity of the CPAC scale was established by using the Abbreviated Torrance Test for Adults (ATTA; Goff \& Torrance, 2002), the Consensual Assessment Technique (CAT; Amabile, 1982) short story task, and the Creativity Styles Questionnaire-Revised (Kumar \& Holman, 1997).

Critical thinking. The Critical Thinking Disposition Inventory (CTDI; Kuo, 2002) was used to assess participants' critical thinking ability. The development of the CTDI was based on the California Critical Thinking Disposition Inventory (CCTDI; Facione, Facione, \& Sanchez, 1992), which includes seven dimensions: (a) truth-seeking, the courage to raise questions and to objectively face the evidence even though it might contradict an individual's interests; (b) open-mindedness, perceiving oneself as unprejudiced, tolerating different opinions, and respecting others' positions; (c) analyticity, continually uncovering potential difficulties and clarifying problems in order to face challenges and find solutions; (d) systematicity, focusing on current tasks and determining to solve related problems in an orderly manner; (e) critical thinking self-confidence, trusting one's self-reasoning abilities rather than blindly believing in others or authority figures; (f) inquisitiveness, strong curiosity, eagerness, and willingness to understand and learn problems solving procedures and explore a wide range of issues; (g) maturity, tolerating unambiguity while dealing with problems or making decisions and discretely judging all possible and reasonable opinions.

The CTDI involves five dimensions: truth-seeking, open-mindedness, analyticity, systematicity, and inquisitiveness. It is a 33-statement instrument with a five-point system, which ranges from 1 "totally 
disagree" to 5 "totally agree." Kuo (2002) reported an acceptable Cronbach's $\alpha$ from .408 to .795. The construct validity was also supported by factor analysis, which explains the $46.03 \%$ variance.

\section{Procedure}

The participants were asked to complete three instruments online, because this course was held in a PC lab. The research team used Google Forms to create a survey and provided its online link to students. Our students were informed that participating in this survey was part of the course requirement and that it would help the instructor to better understand his or her perceived learning environment. The entire procedure took about 20 minutes to complete, after which all concerns were addressed and questions were answered by the researcher who was participating in the session.

\section{Results}

\section{Correlation Analysis}

Table 1 shows the means, standard deviations, and intercorrelations among six variables (idea manipulation, idea generation, flow, imagery/sensory perception, incubation, and metaphorical/analogical thinking) of creative thinking and five variables (truth-seeking, openmindedness, analyticity, systematicity, and inquisitiveness) of critical thinking. The relationship among the 11 variables was investigated using the Pearson product-moment correlation coefficient. All coefficients were positive and significant $(p<.01)$, with strengths from medium $(r=.328)$ to high $(r=.932)$.

Table 1. Means, Standard Deviations, and Intercorrelations for Scores on 11 Measures

\begin{tabular}{lccccccccccccc}
\hline Measure & $\boldsymbol{M}$ & $\mathbf{S D}$ & $\mathbf{1}$ & $\mathbf{2}$ & $\mathbf{3}$ & $\mathbf{4}$ & $\mathbf{5}$ & $\mathbf{6}$ & $\mathbf{7}$ & $\mathbf{8}$ & $\mathbf{9}$ & $\mathbf{1 0}$ & $\mathbf{1 1}$ \\
\hline 1. Idea manipulation & 3.74 & .71 & -- & & & & & & & & & & \\
2. Imagery/ & 3.65 & .71 & .759 & -- & & & & & & & & & \\
$\quad$ Sensory perception & & & & & & & & & & & & & \\
3. Flow & 3.97 & .77 & .622 & .657 & -- & & & & & & & \\
4. Metaphorical/ & & & & & & & & & & & & \\
$\quad$ Analogical thinking & 3.70 & .66 & .778 & .715 & .559 & -- & & & & & & \\
5. Idea generation & 3.68 & .62 & .828 & .772 & .614 & .752 & -- & & & & & \\
6. Incubation & 3.14 & .72 & .412 & .447 & .393 & .379 & .464 & -- & & & & \\
7. Analyticity & 4.39 & .88 & .659 & .675 & .616 & .638 & .662 & .318 & -- & & & & \\
8. Open-mindedness & 4.22 & .85 & .576 & .627 & .514 & .573 & .598 & .353 & .862 & -- & & & \\
9. Truth-seeking & 4.15 & .89 & .546 & .613 & .498 & .574 & .579 & .328 & .851 & .874 & -- & & \\
10. Systematicity & 4.45 & .93 & .623 & .630 & .613 & .653 & .626 & .310 & .932 & .840 & .813 & -- & \\
11. Inquisitiveness & 4.30 & .89 & .625 & .692 & .598 & .601 & .646 & .347 & .923 & .885 & .865 & .865 & -- \\
\hline
\end{tabular}

Note. All coefficients are significant at $\mathrm{p}<.01$. 


\section{Group Differences}

In order to understand the possible differences in creative and critical thinking between genders and residency statuses (Mainland China or Macau), we used an independent-samples t-test to compare the mean scores of the 11 measures. Table 2 shows that, in terms of gender, there were no significant differences between males and females in the 11 measures. In terms of residency status, there were no significant differences in the six measures of creative thinking between students from Mainland China and Macau. However, in critical thinking, significant differences were found in the measures of analyticity, truth-seeking, systematicity, and inquisitiveness, although there was no significant difference in open-mindedness, as can be seen in Table 3.

Table 2. Gender Differences on 11 Measures

\begin{tabular}{lcccccc}
\hline \multirow{2}{*}{\multicolumn{1}{c}{ Measure }} & \multicolumn{2}{c}{ Male } & \multicolumn{2}{c}{ Female } & \\
\cline { 2 - 5 } \multicolumn{1}{c}{$\boldsymbol{M}$} & $\boldsymbol{M}$ & $\boldsymbol{S D}$ & $\boldsymbol{M}$ & $\boldsymbol{S D}$ & $\boldsymbol{t}(\mathbf{1 3 8})$ & $\boldsymbol{p}$ \\
\hline Idea manipulation & 3.71 & .72 & 3.76 & .70 & -.40 & .688 \\
Imagery/Sensory perception & 3.63 & .73 & 3.67 & .70 & -.36 & .717 \\
Flow & 4.00 & .78 & 3.95 & .78 & .38 & .703 \\
Metaphorical/Analogical thinking & 3.64 & .64 & 3.75 & .68 & -.94 & .349 \\
Idea generation & 3.68 & .61 & 3.68 & .63 & .001 & .999 \\
Incubation & 3.23 & .58 & 3.07 & .81 & 1.25 & .213 \\
Analyticity & 4.30 & .91 & 4.46 & .85 & -1.07 & .285 \\
Open-mindedness & 4.17 & .91 & 4.27 & .80 & -.64 & .524 \\
Truth-seeking & 4.08 & .92 & 4.21 & .87 & -.85 & .400 \\
Systematicity & 4.34 & .99 & 4.53 & .88 & -1.19 & .236 \\
Inquisitiveness & 4.23 & .93 & 4.36 & .87 & -.82 & .412 \\
\hline
\end{tabular}


Table 3. Residency Status Differences on 11 Measures

\begin{tabular}{lcccccc}
\hline \multirow{2}{*}{\multicolumn{1}{c}{ Measure }} & \multicolumn{2}{c}{ Mainland China } & \multicolumn{2}{c}{ Macau } & & \\
\cline { 2 - 5 } & $\boldsymbol{M}$ & $\boldsymbol{S D}$ & $\boldsymbol{M}$ & $\boldsymbol{S D}$ & $\boldsymbol{t}(\mathbf{1 3 8})$ & $\boldsymbol{p}$ \\
\hline Idea manipulation & 3.78 & .73 & 3.59 & .60 & 1.34 & .174 \\
$\begin{array}{l}\text { Imagery/Sensory } \\
\text { perception }\end{array}$ & 3.71 & .73 & 3.46 & .59 & 1.79 & .081 \\
Flow & & & & & & \\
Metaphorical/Analogical & 3.01 & .79 & 3.82 & .70 & 1.20 & .237 \\
thinking & & .69 & 3.61 & .52 & .83 & .407 \\
Idea generation & 3.69 & .65 & 3.64 & .48 & .33 & .743 \\
Incubation & 3.12 & .74 & 3.22 & .67 & -.65 & .516 \\
Analyticity & 4.47 & .92 & 4.11 & .67 & 2.40 & .019 \\
Open-mindedness & 4.28 & .89 & 4.04 & .66 & 1.61 & .112 \\
Truth-seeking & 4.22 & .95 & 3.92 & .60 & 2.09 & .040 \\
Systematicity & 4.53 & .97 & 4.16 & .74 & 2.27 & .027 \\
Inquisitiveness & 4.38 & .94 & 4.03 & .64 & 2.43 & .017 \\
\hline
\end{tabular}

In previous analyses, we found that there were significant differences in critical thinking between students from Mainland China and students from Macau. In order to further understand possible interactions between genders and residency statuses in creative and critical thinking, we conducted a multivariate analysis of variance (MANOVA). In this analysis, the 11 measures of creative and critical thinking were treated as dependent variables, and gender and residency status were treated as independent variables. However, because we were conducting a whole series of analyses, we ran the risk of an inflated Type 1 error. In order to minimize for the Type 1 error across multiple tests, we implemented a Bonferroni adjustment by dividing .05 by 11 (which equals .005 after rounding) as our cut-off.

A two-way between-groups MANOVA was performed to investigate gender and residency status differences among 11 measures of creative and critical thinking. Table 4 shows that there was no statistically significant difference between males and females on the combined dependent variables: $\mathrm{F}(11,126)=.59, p=.831$, Wilks's Lambda $=.95$, partial eta squared $=$ .05 . When the results for the dependent variables were considered separately, there was no difference to reach statistical significance via using a Bonferroni adjusted alpha level of .005. In terms of residency status, there was no statistically significant difference between students from Mainland China and from Macau on the combined dependent variables, F $(11,126)=$ $1.24, p=.27$, Wilks's Lambda $=.90$, partial eta squared $=.1$. When the results for the dependent variables were considered separately, there was no difference to reach statistical significance via using a Bonferroni adjusted alpha level of .005. With regard to the interaction between gender and residency status, there was, again, no statistically significant difference on 
the combined dependent variables, $\mathrm{F}(11,126)=.39, p=.96$, Wilks's Lambda $=.97$, partial eta squared $=.03$. Furthermore, when the results for the dependent variables were considered separately, there was no difference to reach statistical significance using the Bonferroni adjusted alpha level of .005 .

\section{Structural Equation Modeling}

In our study, structural equation modeling was performed with IBM AMOS to further test the model structure. We used the indicators recommended by Hair, Black, Babin, and Anderson (2010) and Tabachnick and Fidell (2001) to assess goodness of model fit: Goodness-of-Fit Index (GFI; greater than .90 typically considered good), Comparative Fit Index (CFI; above .90 usually indicating good fit), Incremental Fit Index (IFI; above .90 usually indicating good fit), and Root Mean Square Error of Approximation (RMSEA; lower than .08 indicating an acceptable fit). The results show that the model yielded a good fit: ${ }^{2}=50.82, d f=37, p=$ $.065, \mathrm{GFI}=.939, \mathrm{CFI}=.992, \mathrm{IFI}=.992, \mathrm{RMSEA}=.052$. Figure 1 shows the factor loadings results from .49 to .96; all coefficients were significant at $p<.001$.

With regard to convergent validity, based on criteria suggested by Hair et al. (2010), all factor loadings should be significant and standard-loading estimates should be above .50. An average variance extracted (AVE) of .5 suggests adequate convergence, and the construct reliability (CR) estimate of .7 or higher suggests good reliability. In our model, all factor loadings were significant and standard-loading estimates were above .50 with $\mathrm{AVE}=.74$ and $\mathrm{CR}=.97$, which suggest that this model achieved convergent validity.

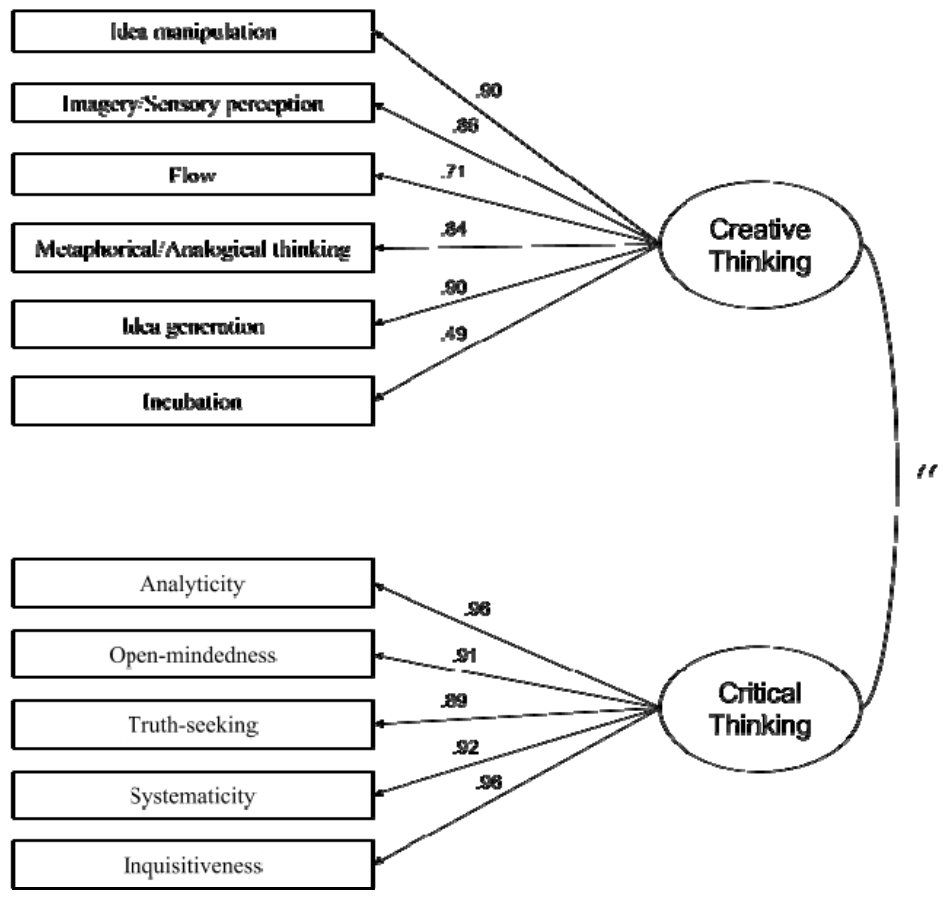

Figure 1. Standardized coefficients for the model. Latent constructs are shown in ellipses, and observed variables are shown in rectangles. All coefficients are significant at $p<.01$. 
Table 4. Multivariate and Univariate Analyses of Variance F Ratios for Gender $\times$ Status for 11 Measures

\begin{tabular}{|c|c|c|c|c|c|c|c|c|c|c|c|c|}
\hline \multirow[b]{2}{*}{$\begin{array}{l}\frac{0}{0} \\
\frac{\pi}{\pi} \\
\frac{\pi}{\pi} \\
\frac{\pi}{5}\end{array}$} & \multirow[b]{2}{*}{ 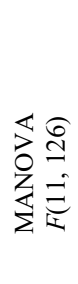 } & \multicolumn{11}{|c|}{ ANOVA $F(1,136)$} \\
\hline & & 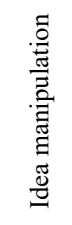 & 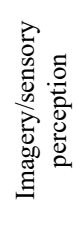 & $\frac{3}{d x}$ & 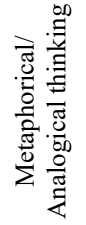 & 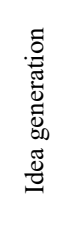 & 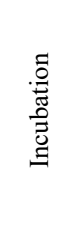 & 离 & 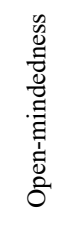 & 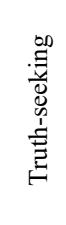 & 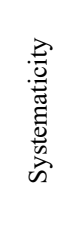 & 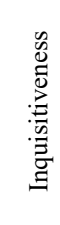 \\
\hline Gender (G) & .59 & 1.20 & .82 & .03 & 1.04 & .21 & 1.35 & 1.76 & .80 & .83 & 1.40 & 1.17 \\
\hline Status (S) & 1.24 & 2.41 & 3.58 & 1.64 & .82 & .20 & .50 & 4.51 & 2.09 & 2.83 & 3.99 & 4.25 \\
\hline $\mathrm{G} \times \mathrm{S}$ & .39 & 1.69 & 1.02 & 67 & .16 & .65 & .04 & .47 & .35 & .10 & .07 & .39 \\
\hline
\end{tabular}

Note. $F$ ratios are Wilks's approximation of $F$. ANOVA = univariate analysis of variance; MANOVA $=$ multivariate analysis of variance.

\section{Discussion}

This study was conducted to examine the relationship between creative and critical thinking of undergraduates in Macau. The results indicate that in our sample creative and critical thinking are positively closely related. On the basis of zero-order correlation, we found that the strength of correlations among six creative thinking and five critical thinking variables were between medium and high. This finding is supported by the creative process models proposed by the students of creativity (Mumford \& Gustafson, 1988; Treffinger \& Isaksen, 2005). In their models, two basic stages are the generation stage and the evaluation stage. In the generation process, creative thinking is the key and the goal is to produce diverse ideas or solutions to the problems students encounter. In evaluation, critical thinking plays a major role in assessing the practical value of their ideas to best fit the scenario. In this sense, two attributes are generally accepted to define creativity: originality and usefulness (Runco \& Jaeger, 2012).

When we compared the group differences of creative and critical thinking, in terms of gender, the results showed that there was no significant difference between male and female students. However, when we compared students from Mainland China to those from Macau, the results showed that only critical thinking was significantly different. More specifically, except for open-mindedness, students from Mainland China had higher scores than their counterparts in the four other variables of critical thinking. It therefore seems that open-mindedness is more related to creative thinking. In our sample, we found no significant difference in creative thinking with regard to the residency status of students. As a result, the difference of openmindedness in critical thinking between the two groups was not significant. On the other hand, it is possible that different educational backgrounds contributed to their different critical thinking preferences. It has been claimed that teaching philosophy and pedagogy in Mainland China is more stressful than rote learning and top-down learning. Learning logic and reasoning is more important than creative thinking in Chinese classrooms (Tsai \& Özturgut, 2013). Nevertheless, in Macau the educational atmosphere is more open and more Western-oriented. 
Part of the reason is that Macau was a colony of Portugal and although it is now a part of China, its educational system is still different from the Mainland.

We further investigated whether there was any interaction between gender and residency status on students' creative and critical thinking. In addition, we used the univariate analysis of variance of gender and residency status on the two types of thinking. The results indicated that there was no interaction between gender and residency status and that neither variable had any effect on the six measures of creative thinking or on the five measures of critical thinking.

In order to further validate our findings of the relationship between creative and critical thinking, we conducted structural equation modeling. The proposed model fit our data well and we found that the relationship between creative and critical thinking was strong and positive $(r$ $=.77$ ). It seems that this robust result extends the existing literature, sheds lights on future studies, and provides some practical implications. As Tsai $(2012,2013)$ has argued, creative and critical thinking are a necessary skill for students to learn. In this sense, these two elements should be included in the curriculum and educational policy and teachers should facilitate these two thinking modes in the classroom.

\section{Limitations}

In drawing our findings, some salient limitations should be noted. First, the cross-sectional design of the current study may limit the explanation of our findings as we could not validate the causal relations between creative and critical thinking. Future studies may utilize longitudinal or experimental designs to measure and compare the creative and critical thinking of undergraduates. Second, although the model fit the data well, the predicative validity could be stronger. This result could be due to high correlations between some of the variables. A third limitation is the use of self-reported measures rather than expert evaluations or behavioral measures. Future studies could use real-life measures of individuals' creative and critical thinking to validate our findings. Finally, our homogeneous sample might have influenced the results of the current study. Further research could use a more diverse sample and include ethnic groups to generalize and validate the relationship between creative and critical thinking.

\section{Implications}

Although the limitations of this study must be kept in mind, the results of the current study provide useful insights into the relationship between creative and critical thinking. Our research findings are significant to the education professional. Educators should not only consider how to include creative and critical thinking into their classrooms, but also how to cultivate these two thinking modes among their students.

In our study, we found that in terms of creative thinking, students from Mainland China and Macau had similar results; nevertheless, with regard to critical thinking, students from Mainland China outperformed those from Macau. As a result, it is recommended that educators in Macau should [lace emphasis on the development of critical thinking via learning practice and curriculum reform. 
Taken together, inspired by the creative process models that have been mentioned earlier, it is suggested that teachers could use real-world scenarios as stimuli to practice creative and critical thinking. Teachers can first ask students to generate as many solutions and ideas as they can and then critically scrutinize and evaluate these ideas. This process may be time consuming, but this practice is promising.

\section{Conclusion}

The main objective of this study was to examine the relationship between creative and critical thinking among art and design undergraduates in Macau. Two major findings were recorded. Creative and critical thinking were positively correlated among our Chinese undergraduates and this correlation was strong. Furthermore, creative thinking was similar between students from Mainland China and from Macau; nevertheless, students from Mainland China had better critical thinking abilities than students from Macau. Although there were some salient limitations in the current study, it remains of importance and value. Future research in this line of study seems promising and deserves more attention. Additionally, our front-line teachers should be encouraged to promote creative and critical thinking in the classroom.

\section{References}

Amabile, T. M. (1982). Social psychology of creativity: A consensual assessment technique. Journal of Personality and Social Psychology, 45, 997-1013.

Amabile, T. M. (1996). Creativity in context: Update to the social psychology of creativity. Boulder, CO: Westview Press.

Atabaki, A. M. S., Keshtiaray, N., \& Yarmohammadian, M. H. (2015). Scrutiny of critical thinking concept. International Education Studies, 8(3), 93-102.

Baer, J., Kaufman, J. C., \& Gentile, C. A. (2004). Extension of the consensual assessment 116 technique to nonparallel creative products. Creativity Research Journal, 16(1), 113-117.

Baer, J., \& McKool, S. S. (2014). The gold standard for assessing creativity. International Journal of Quality Assurance in Engineering and Technology Education, 3(1), 81-93. http://doi.org/10.4018/ijqaete.2014010104

Baughman, W. A., \& Mumford, M. D. (1995). Process-Analytic models of creative capacities: Operations influencing the combination-and-reorganization process. Creativity Research Journal, 8(1), 37-62.

Bloch, J., \& Spataro, S. E. (2014). Cultivating critical-thinking dispositions throughout the business curriculum. Business and Professional Communication Quarterly, 77(3), 249-265.

Brodin, E. M. (2016). Critical and creative thinking nexus: Learning experiences of doctoral students. Studies in Higher Education, 41(6), 971-989.

Chun, M.-S., Kang, K., Kim, Y. H., \& Kim, Y. M. (2015). Theme-based project learning: Design and application of convergent science experiments. Universal Journal of Educational Research, 3(11), 937-942.

Ennis, R. H., \& Millman, J. (1985). Cornell Critical Thinking Test. Pacific Grove, CA: Midwest Publications.

Facione, P. A. (2000). The California Critical Thinking Skills Test: CCTST-2000. San Jose, CA: California Academic Press.

(C) Psy, Soc, \& Educ, 2019, Vol. 11(3) 
Facione, P. A., Facione, N. C., \& Giancarlo, C. A. (1998). The disposition toward critical thinking: Its character, measurement, and relationship to critical thinking skill. Informal Logic, 20(1), 61-84.

Fordham, H. (2015). Disembodied creativity: The role of action research in moderating educator expectations of marketing and public relations students. Journal of University Teaching and Learning Practice, 12(4), Article 3.

Glassner, A., \& Schwarz, B. B. (2007). What stands and develops between creative and critical thinking? Argumentation? Thinking Skills and Creativity, 2(1), 10-18.

Goff, K., \& Torrance, E. P. (2002). Abbreviated Torrance test for adults manual. Bensenville, IL: Scholastic Testing Service.

Hair, J. F., Black, W. C., Babin, B. J., \& Anderson, R. E. (2010). Multivariate data analysis: A global perspective. Upper Saddle River, NJ: Pearson/Prentice Hall.

Halpern, D. F. (2010). Creativity in college classroom. In R. A. Beghetto \& J. C. Kaufman (Eds.), Nurturing creativity in the classroom (pp. 380-393). New York, NY: Cambridge University Press.

Hocevar, D. (1979). Ideational fluency as a confounding factor in the measurement of originality. Journal of Educational Psychology, 71, 191-196.

Hocevar, D., \& Bachelor, P. (1989). A taxonomy and critique of measurements used in the study of creativity. In J. A. Glover, R. R. Ronning, \& C. R. Reynolds (Eds.), Handbook of creativity (pp. 53-75). New York, NY: Plenum Press.

Hoofd, I. (2010). Singapore: Bridgehead of the West or counterforce? The stimulation of creative and critical thought in Singapore's higher education policies. Globalisation, Societies and Education, 8(2), 295-305.

Huber, C. R., \& Kuncel, N. R. (2016). Does college teach critical thinking? A meta-analysis. Review of Educational Research, 86(2), 431-468.

Kaufman, J. C., Lee, J., Baer, J., \& Lee, S. (2007). Captions, consistency, creativity and the consensual assessment technique: New evidence of reliability. Thinking Skills and Creativity, 2(2), 96-106.

Karakas, S. L. (2010). Creative and critical thinking in the arts and sciences: Some examples of congruence. Forum on Public Policy Online, 2, 1-9.

Kim, K. H. (2006). Can we trust creativity tests? A review of the Torrance Tests of Creative Thinking (TTCT). Creativity Research Journal, 18, 3-14.

Koray, O., \& Koksal, M. S. (2009). The effect of creative and critical thinking based laboratory applications on creative and logical thinking abilities of prospective teachers. AsiaPacific Forum on Science Learning and Teaching, 10, 1-13.

Kuo, L.-C. (2002). Experiment on teaching critical thinking in social studies of the elementary school. Unpublished Thesis. Retrieved from http://handle.ncl.edu.tw/11296/ndltd/68386848146806897309

Kumar, V. K., \& Holman, E. R. (1997). The Creativity Styles Questionnaire-Revised. Unpublished psychological test. Department of Psychology, West Chester University of Pennsylvania, West Chester, PA.

Liu, Z. K., He, J., \& Li, B. (2015). Critical and creative thinking as learning processes at topranking Chinese middle schools: Possibilities and required improvements. High Ability Studies, 26(1), 139-152. 
McWilliam, E., \& Dawson, S. (2008). Teaching for creativity: Towards sustainable and replicable pedagogical practice. Higher Education, 56(6), 633-643.

Miller, A. L. (2009). Cognitive processes associated with creativity: Scale development and validation. Muncie, IN: Ball State University. Retrieved from http://cardinalscholar.bsu.edu/763/1/Amiller 2009-2 BODY.pdf

Mumford, M. D., \& Gustafson, S. B. (1988). Creativity syndrome: Integration, application, and innovation. Psychological Bulletin, 103(1), 27-43.

O’Donnell, S., \& Micklethwaite, C. (1999). International review of curriculum and assessment frameworks. Thematic probe: Arts and creativity in education. An international perspective. Retrieved from www.inca.org.uk/pdf/1999_creativity_and_arts.pdf

Runco, M. A., \& Chand, I. (1995). Cognition and creativity. Educational Psychology Review, 7(3), 243-267.

Runco, M. A., \& Jaeger, G. J. (2012). The standard definition of creativity. Creativity Research Journal, 24(1), 92-96.

Shaw, R. D. (2014). How critical is critical thinking? Music Educators Journal, 101(2), 65-70.

Silvia, P. J., Winterstein, B. P., Willse, J. T., Barona, C. M., Cram, J.T., Hess, K. I., et al., (2008). Assessing creativity with divergent thinking tasks: Exploring the reliability and validity of new subjective scoring methods. Psychology of Aesthetics, Creativity, and the Arts, 2, 68-85.

Sternberg, R. J. (2003). Creative thinking in the classroom. Scandinavian Journal of Educational Research, 47(3), 325-338.

Tabachnick, B. G., \& Fidell, L. S. (2001). Using multivariate statistics. Boston, MA: Allyn and Bacon.

Torrance, E. P. (1974). The Torrance Tests of Creative Thinking-Norms-Technical Manual Research Edition-Verbal Tests, Forms $A$ and B-Figural Tests, Forms $A$ and $B$. Princeton, NJ: Personnel Press.

Treffinger, D. J., \& Isaksen, S. G. (2005). Creative problem solving: The history, development, and implications for gifted education and talent development. Gifted Child Quarterly, 49(4), 342-353.

Tsai, K. C. (2012). Dance with critical thinking and creative thinking in the classroom. Journal of Sociological Research, 3(2), 312-324.

Tsai, K. C. (2013). Being a critical and creative thinker: A balanced thinking mode. Asian Journal of Humanities and Social Sciences, 1(2), 1-9.

Tsai, K. C., \& Özturgut, O. (2013). PISA and beyond: What can we learn from Asian education. Pacific - Asian Education Journal, 25(2), 5-16.

U.S. Department of Education, National Center for Education Statistics (2000). The NPEC sourcebook on assessment, volume 1: Definitions and assessment methods for critical thinking, problem solving, and writing, NCES 2000-172. In T. D. Erwin (Ed.), For the Council of the National Postsecondary Education Cooperative Student Outcomes Pilot Working Group: Cognitive and Intellectual Development. Washington, DC: U.S. Government Printing Office. 